\title{
The influence of static and RF field heterogeneity on T1rho cardiovascular MRI
}

\author{
Qiao Han ${ }^{1 *}$, Yuchi Han ${ }^{1}$, Robert C Gorman ${ }^{2}$, Walter R Witschey ${ }^{2}$ \\ From 17th Annual SCMR Scientific Sessions \\ New Orleans, LA, USA. 16-19 January 2014
}

\begin{abstract}
Background
Spin lock or T1rho MRI methods may be very useful for assessing myocardial disease. Recently, we reported that there is significant low field relaxation dispersion in myocardial and fibrotic scar tissue during in vivo T1rho MRI, contributing to contrast enhancement compared to spin echo (T2) MRI. However, we also observed that differences in magnetic field susceptibility between the heart and lung organs and poor RF penetration and field homogeneity in large patients and at $3 \mathrm{~T}$ contribute to T1rho quantification errors. Our goal was to determine the influence of static $\left(B_{0}\right)$ and $R F\left(B_{1}\right)$ heterogeneity on in vivo myocardial T1rho quantification.
\end{abstract}

\section{Methods}

We performed simulations and experiments to explore how $B_{0}$ and $B_{1}$ field heterogeneity influences T1rho MRI. Tilted rotating frame (TRF) Bloch simulations were performed for a rotary-echo spin lock, varying field heterogeneity and spin lock duration (TSL $=2-50 \mathrm{~ms}$, $\mathrm{B}_{1}=60-140 \%$ nominal spin lock, and $\Delta \mathrm{B}_{0}=-2-2 \mathrm{ppm}$ at $1.5 \mathrm{~T})$ with random Gaussian noise $(\sigma=1-20 \%$ of initial magnetization). Phantom experiments were performed using a homogeneous $\mathrm{H}_{2} \mathrm{O}$ cylinder $\left(\mathrm{MnCl}_{2}=\right.$ $0.016 \%)$. In vivo experiments were performed in Yorkshire swine $(n=5)$. Simulated phantom and in vivo images were derived from $B_{0}$ and $B_{1}$ maps using the TRF Bloch simulations and were correlated with experimental images at the same spin lock duration.

\section{Results}

We investigated the effect of field heterogeneity on measured T1rho relaxation times in simulations, phantom experiments and in vivo. T1rho artifacts were characterized by banding artifacts resulting from incomplete longitudinal restoration of the T1rho-prepared magnetization, leading to RF field heterogeneity and rotation about the effective field during the spin lock pulse. These artifacts were most prominent at the LV posterolateral wall where significant static field heterogeneity $( \pm 200 \mathrm{~Hz})$ could result in nutation about an effective field oriented away from the idealized spin lock axis. In vivo results correlated well with simulations and phantoms experiments. Measured T1rho relaxation times in the three identical compartments were constant in the homogeneous $\mathrm{B}_{0}$ field and in the $50 \mathrm{mT} / \mathrm{m}$ field gradient in which the $B_{0}$ field was less than $50 \mathrm{~Hz}$ off-resonance. Noticeable variations were observed at $100 \mathrm{~Hz}$ off-resonance $(100 \mathrm{mT} / \mathrm{m}$ gradient). The $B_{0}$ field in vivo is much less homogeneous than that for the phantom; therefore the T1rho images show much more complex patterns (Figure 1C). Mean $B_{0}$ and $B_{1}$ field over the left ventricle in the short axis view of the pig heart in vivo are in ranged -85.14 to $34.7 \mathrm{~Hz}$ and 244.30 to $361.87 \mathrm{~Hz}$ respectively with $95 \%$ confidence interval.

\section{Conclusions}

Spin lock artifacts were the result of static field heterogeneity predominantly confined to the left ventricular posterolateral wall. Static field heterogeneity should be reduced to less than $10 \%$ of the spin lock field amplitude to minimize T1rho quantification errors.

\section{Funding}

The authors gratefully acknowledge support from the National Institutes of Health through awards K99HL108157 and R01HL63904. 


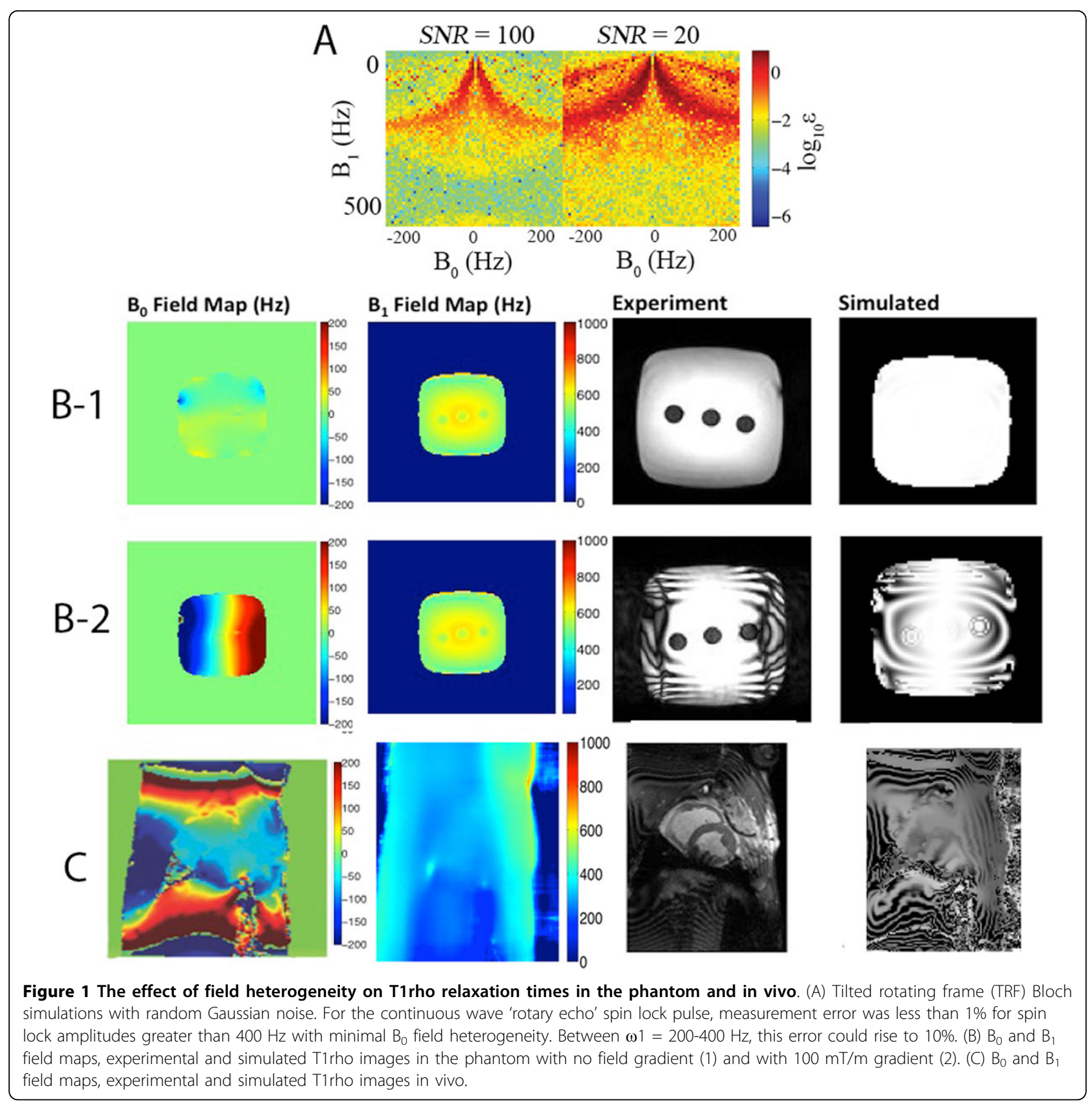

Table 1

\begin{tabular}{|c|c|c|c|c|c|c|c|}
\hline \multicolumn{5}{|c|}{ Phantom } & \multicolumn{3}{|c|}{ in vivo } \\
\hline & Gradient & Tube 1 & Tube 2 & Tube 3 & & Mean & Range \\
\hline \multirow[t]{3}{*}{$\mathrm{B}_{0}(\mathrm{~Hz})$} & No gradient & $16.89 \pm 0.96$ & $14.25 \pm 0.80$ & $8.68 \pm 3.75$ & $\mathrm{~B}_{0}(\mathrm{~Hz})$ & -25.21 & $-85.14-34.7$ \\
\hline & $50 \mathrm{mT} / \mathrm{s}$ & $-43.86 \pm 5.58$ & $14.18 \pm 5.04$ & $77.97 \pm 7.63$ & & & \\
\hline & $100 \mathrm{mT} / \mathrm{s}$ & $-103.43 \pm 10.73$ & $14.97 \pm 10.21$ & $148.84 \pm 12.65$ & & & \\
\hline $\mathrm{B}_{1}(\mathrm{~Hz})$ & All gradient levels & $546.38 \pm 6.96$ & $14.24 \pm 0.80$ & $541.50 \pm 4.21$ & $\mathrm{~B}_{1}(\mathrm{~Hz})$ & 303.01 & 244.29-361.87 \\
\hline \multirow[t]{3}{*}{ T1Rho (ms) } & No gradient & $47.28 \pm 2.92$ & $47.25 \pm 2.97$ & $44.99 \pm 3.06$ & T1Rho-Septum (ms) & 55.55 & $50.13-60.97$ \\
\hline & $50 \mathrm{mT} / \mathrm{s}$ & $43.02 \pm 3.34$ & $48.57 \pm 2.92$ & $45.57 \pm 3.25$ & T1Rho-Anterior (ms) & 55.27 & $46.29-64.24$ \\
\hline & $100 \mathrm{mT} / \mathrm{s}$ & $59.40 \pm 8.88$ & $42.50 \pm 4.02$ & $63.26 \pm 7.12$ & T1Rho-Posterolateral (ms) & 60.60 & $45.64-75.57$ \\
\hline
\end{tabular}




\title{
Authors' details
}

${ }^{1}$ Cardiology, University of Pennsylvania, Philadelphia, Pennsylvania, USA.

${ }^{2}$ Surgery, University of Pennsylvania, Philadelphia, Pennsylvania, USA.

Published: 16 January 2014

\author{
doi:10.1186/1532-429X-16-S1-P70 \\ Cite this article as: Han et al:: The influence of static and RF field \\ heterogeneity on T1rho cardiovascular MRI. Journal of Cardiovascular \\ Magnetic Resonance 2014 16(Suppl 1):P70.
}

Submit your next manuscript to BioMed Central and take full advantage of:

- Convenient online submission

- Thorough peer review

- No space constraints or color figure charges

- Immediate publication on acceptance

- Inclusion in PubMed, CAS, Scopus and Google Scholar

- Research which is freely available for redistribution 